\title{
O lugar do sagrado no pensamento de Michel Maffesoli
}

\section{The place of the sacred in the thought of Michel Maffesoli}

\author{
Carlos Eduardo Souza AGUIAR ${ }^{1}$
}

\begin{abstract}
Resumo
O objetivo deste artigo é compreender a centralidade da noção de sagrado no pensamento de Michel Maffesoli. Primeiramente, abordaremos a releitura maffesoliana da modernidade como a época do desencantamento do mundo, retomando as análises clássicas de Max Weber. Em seguida, destacaremos como para Maffesoli a saturação do moderno significa o retorno do que ele chama de sacral, neologismo utilizado para destacar a necessidade coletiva de comunhão emocional e de reconexão com o outro, seja este o outro social, natural ou divino. Finalmente, investigaremos qual é o papel da tecnologia nesse processo de reencantamento do mundo, destacando a clássica definição de Maffesoli da pós-modernidade como a sinergia entre o arcaico e o desenvolvimento tecnológico.
\end{abstract}

Palavras-chave: Michel Maffesoli; Sagrado; Tecnologia; Pós-modernidade; Imaginário.

\begin{abstract}
This article aims to understand the centrality of the notion of sacred in the thought of Michel Maffesoli. Firstly, we will approach the Maffesolian re-reading of modernity as the time of disenchantment of the world, by considering the classic analyses of Max Weber. Thereafter, we will highlight how for Maffesoli the saturation of the modern means the return of what he calls the sacral, a neologism used to emphasise the collective need for emotional communion and re-connection with the other, be it social, natural or divine. Finally, we will investigate the role of technology in this process of reenchantment of the world, highlighting Maffesoli's classic definition of postmodernism as the synergy between archaic phenomena and technological development.
\end{abstract}

Keywords: Michel Maffesoli; Sacred; Technology; Postmodernity; Imaginary.

\footnotetext{
${ }^{1}$ Doutor em Sociologia pela Université Sorbonne Paris Cité, mestre em Ciências da Comunicação pela USP, especialista em Ciências da Religião pela PUC-SP e graduado em Filosofia pela FFLCH-USP e em Relações Públicas pela ECA-USP. É professor dos cursos de comunicação social e filosofia da Faculdade Paulus de Tecnologia e Comunicação (Fapcom). E-mail: cadu.s.aguiar@gmail.com.
} 


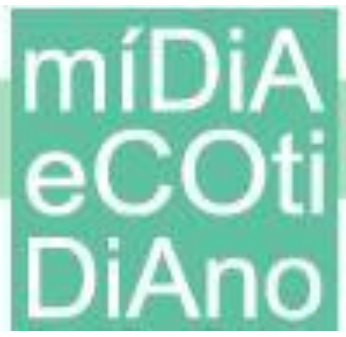

Introdução

Émile Durkheim na conclusão de sua obra incontornável As formas elementares da vida religiosa, interroga-se sobre a produção social do sagrado e faz um diagnóstico preciso da era moderna: "Os velhos deuses estão envelhecendo ou estão mortos, e não nasceram outros" (DURKHEIM, 2008, p. 600, tradução nossa). Com isso, ele nos apresenta um prognóstico surpreendente: "Um dia virá em que nossas sociedades conhecerão novamente horas de efervescência criativa durante as quais novos ideais surgirão" (DURKHEIM, 2008, p. 600, tradução nossa). Anunciado anteriormente por Nietzsche, a temática da morte de Deus é retomada por Durkheim que a vislumbra com uma abertura para uma ampla gama de possibilidades de viver o sagrado. O prognóstico durkheimiano provou ser bastante preciso, afinal o sagrado hoje está em toda parte e o misticismo é encontrado em diferentes situações da vida cotidiana, muito além do arcabouço institucional e sob várias modulações.

Se tomarmos a caracterização de Durkheim de religião como a representação das regras morais da sociedade e da existência coletiva, uma visão alternativa à clássica ideia de secularização aparece. É no seio dessa brecha lançada por Durkheim que Michel Maffesoli estabeleceu um caminho de pensamento ao longo de seus quase 50 anos de vida intelectual, fundamentados na constatação de que vivemos no "tempo das tribos". Contra as teorias que advogam uma crescente individualização ou contra as teorias de uma sociedade de massa que traz a uniformidade e a perda da diferença, Maffesoli sugere que as sociedades pós-modernas são caracterizadas pelo rápido crescimento de pequenos agrupamentos de pessoas que compartilham um gosto comum, seja musical, esportivo, religioso, político etc.

O ponto chave para Maffesoli é que a criação dessas novas tribos - uma manifestação imediata na qual as formas atuam como recipientes e onde o indivíduo aparece como adaptável ao infinito - demonstra a permanência de uma necessidade humana pela busca de contato social e interação. Essa sede contínua pela socialidade ou pela ligação comunitária é, nos termos de Durkheim, uma característica religiosa (MAFFESOLI, 2000). Os antigos Deuses podem estar em declínio, mas essa busca pelo sagrado, que o processo moderno de "desmagização" havia acreditado ter extirpado da existência social, ganha novas formas na contemporaneidade; e são essas novas formas 


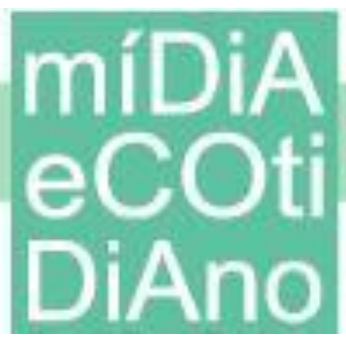

que Maffesoli se esforça para compreender, descrevendo aquilo que é, e não aquilo que deveria ser.

Este artigo buscar destacar essa centralidade do sagrado e da religiosidade no pensamento de Maffesoli. Abordaremos, em um primeiro momento, sua leitura do mundo moderno como a época do desencantamento do mundo, retomando as análises clássicas de Max Weber. Em seguida, é fundamental abordar como para Maffesoli a saturação do mundo moderno significa o retorno do que ele chama de sacral, essa necessidade coletiva de comunhão emocional, de reconexão com o outro social, natural e divino. Finalmente, abordaremos qual é o papel desempenhado pelas novas tecnologias e seus aparatos nesse processo de reencantamento do mundo, papel visto como essencial, pois a própria pósmodernidade é, em sua definição, a sinergia entre os fenômenos arcaicos e o desenvolvimento tecnológico.

\section{O mito do desencantamento do mundo}

Michel Maffesoli ao interpretar a modernidade, época atualmente em declínio, costuma destacar que são três os grandes valores que a estruturam: o progressismo, o individualismo e o racionalismo. Para explicar essa última característica que, no limite, justifica as teses da secularização moderna, Maffesoli se apoia nas clássicas análises de Max Weber para quem o indivíduo moderno é aquele que age e reage sob a ação do racionalismo. A imagem do desencantamento do mundo é utilizada pelo sociólogo alemão para enfatizar esse processo. Lembremos que a palavra desencanto significa, literalmente, remover um feitiço, quebrar um feitiço. Em resumo, quebra-se o feitiço e coloca-se o mundo em ordem a fim de controlá-lo e dominá-lo, tornando-o desmistificado, sem magia (WEBER, 2006).

Ainda segundo Weber, esse processo de evacuação de toda dimensão sobrenatural, atrofiando o lugar do imaginário, foi cumprido em grande escala primeiramente pela versão mais desencantada do cristianismo, o protestantismo, sobretudo com a eliminação da magia sacramental, secundarizando os rituais não-verbais. Evidentemente, o desencantamento foi consolidado e ampliado com o advento da ciência e do humanismo moderno. A partir de então, tudo deveria dar suas razões ou tudo deveria estar submetido à razão. Por meio desse movimento concomitante realizado pela ciência 


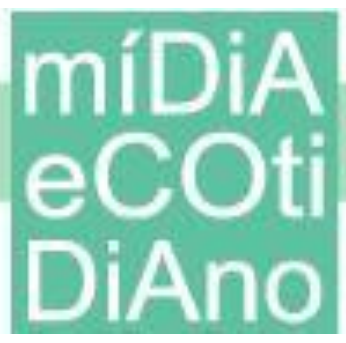

e pela religião, o iconoclasmo foi concretizado e a natureza foi reduzida a algo controlável e objetivo, efetivando, finalmente, o sonho de Descartes prescrito em seu Discurso do método de converter o homem em mestre e possuidor da natureza.

É nessa mesma linha interpretativa que Martin Heidegger, ao caracterizar os tempos modernos, também relata a fuga dos deuses como uma de suas característicaschave:

A desdivinização é o dúplice processo de, por um lado, a imagem do mundo se cristianizar, na medida em que o fundamento do mundo é estabelecido como o infinito, o incondicionado, o absoluto, e, por outro lado, o cristianismo transformar a sua cristianidade numa mundividência (a mundividência cristã) e, deste modo, se modernizar (HEIDEGGER, 2002, p. 70).

Nesse sentido, nada é mais exemplar da aliança pelo desencantamento do mundo do que a tecnologia, campo por excelência da racionalização. A tecnologia é o instrumento pelo qual os elementos mágicos e místicos do mundo são eliminados. Como resultado da racionalidade moderna, as novas máquinas foram projetadas como ferramentas para dominar a natureza e eliminar todos os imprevistos. Vale lembrar que Heidegger interroga-se sobre a essência da técnica alertando para a conveniência em não a confundir com os objetos técnicos: a especificidade da técnica é independente do dispositivo instrumental. Para Heidegger, a essência da técnica, que não é nada de técnico, não está ligada a uma prática, mas a uma maneira de desvelar o mundo.

Nessa relação de desvelamento, há uma ação que pertence à produção, própria da técnica antiga, e aquela que pertence à provocação, característica da moderna tecnologia das máquinas (HEIDEGGER, 2007). A essência da técnica moderna se encontra na armação, isto é, na conversão da natureza em mera fonte de energia. Assim, como destaca Heidegger, "O mundo agora aparece como um objeto no qual o pensamento calculador direciona os seus ataques, e aos seus ataques nada deve resistir" (HEIDEGGER, 1968, p. 141, tradução nossa).

Esse mundo da técnica se levantou contra todos os misticismos e superstições, aleijando-os ao museu dos arcaísmos selvagens, de modo que o sagrado fora assim considerado como um mero resíduo obsoleto, reservado à administração de instituições 
religiosas que o reduzira a formas monoteístas e cada vez mais iconoclastas (FERRAROTTI, 2013). Como nos alerta Maffesoli - retomando os ataques de Nietzsche aos ateístas devotos - a modernidade, ao buscar extirpar a sacralidade, acaba por forjar um novo ideal religioso no qual a razão é ungida à divindade:

Porque o ideal da vida moral que encontra seu ápice no século das Luzes baseia-se sobre uma explicação do mundo mais racional, mais científica, libertado do mito e dos diversos pressupostos obscurantistas. Retrospectivamente, podemos ver em um tal ideal moral a nova religião da modernidade. A religião governada pela deusa razão (MAFFESOLI, 2009 , p. 62, tradução nossa).

Essa compreensão da essência da tecnologia governada pela razão instrumental ajuda a iluminar o tempo presente e entender como no lugar do paraíso terrestre instaurado pela tecnologia - conforme prometido por diversos messianismos modernos promotores de uma religião da tecnicidade, a exemplo de Francis Bacon, SaintSimon, Augusto Comte ou Karl Marx - alcançamos pela valorização sem nuances da liberdade transgressora dos limites, a devastação do mundo e dos espíritos, isto é, “ conseguimos outro objetivo (heteron telos) do que o esperado: um não-mundo, uma devastação do mundo. Efeito perverso, se houver, mas efeito previsível" (MAFFESOLI, 2015, p. 14, tradução nossa). Essa devastação é sintetizada e dramatizada atualmente na hipótese do Antropoceno, um termo da cronologia geológica proposto para caracterizar a época da história da Terra na qual as ações humanas, sobretudo a partir do emprego da tecnologia, tiveram um impacto global e significativo sobre o ecossistema terrestre (BONNEUIL; FRESSOZ, 2016).

Desde suas primeiras obras e de modo absolutamente inovador, Maffesoli antecipou todo esse debate que está na ordem do dia, buscando compreender as origens míticas da forma social moderna por excelência conhecida como progresso. Isto é, para Maffesoli existia um mito no coração do mundo moderno, apesar da oposição mantida entre pensamento racional e mítico, entre ciência e religião. Esse mito do progresso ou ideologia do progressismo era disseminado por uma espécie de catecismo laico, inscrevendo-se, portanto, na própria economia da vida social. Trata-se, no limite, de 


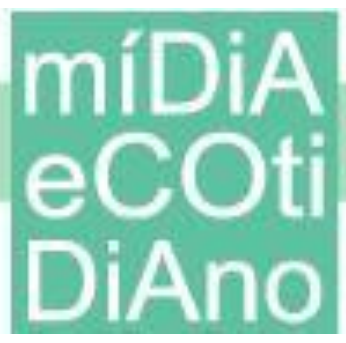

formas profanas de religião, ou, mais especificamente, uma pseudomorfose da religião (MAFFESOLI, 1979).

Se reconhecemos como mito o próprio ideal da destruição do mito, a consequência, como nos lembra Gianni Vattimo, é que o desencantamento do mundo também levou a um absoluto desencanto da própria ideia de desencantamento (VATTIMO, 1998). Isso significa que Deus ressuscitou ou que nunca esteve realmente morto? A resposta a essa questão complexa nos exige uma compreensão clara da afirmação de Nietzsche sobre a morte de Deus, mais ligada à crítica da metafísica, presente no pensamento ocidental desde Platão, do que ao sagrado. A ideologia ateia do progresso é, no limite, uma continuação da tradição cristã, porém sem o Deus que a sancionava. $\mathrm{O}$ anúncio da morte de Deus é direcionado, portanto, aos ateus modernos que colocaram o reino de Deus no futuro, na terra, no humano, conservando-se a fé no antigo ideal (NIETZSCHE, 2006).

As principais ideias que justificaram o ateísmo moderno estão em crise, como o cientificismo positivista, o historicismo hegeliano e o marxismo, de modo que as teses da secularização da sociedade ocidental, isto é, o declínio do religioso e a hipotética superação da idade sacra a era tecnológica parece incoerente, porque não vivemos mais em um mundo desencantado, ao contrário, vimos uma verdadeira rebelião do imaginário (DURAND, 2010). Vale a pena lembrar o que Mircea Eliade disse a esse respeito: "Estamos compreendendo hoje algo que o século XIX não poderia nem mesmo prever: que o símbolo, o mito, a imagem pertencem à substância da vida espiritual, podemos camuflá-los, degradá-los, mutilá-los, mas nunca serão extirpados" (ELIADE, 2013, p. 16, tradução nossa). A morte de Deus, no limite, abre espaço para uma outra vivência do sagrado. Logo, as múltiplas efervescências e o retorno vigoroso do magnetismo e mistério arcaicos que caracterizam a cultura contemporânea são indícios, de acordo com Maffesoli, de um verdadeiro reencantamento do mundo.

\section{O sacral pós-moderno}

Está no centro da compreensão de Maffesoli acerca da pós-modernidade o diagnóstico da saturação dos valores modernos: o progressismo se revela enquanto mito na medida em que o ideal utópico da instauração do paraíso sobre a terra é desmentido 
pelo colapso ambiental; o individualismo está em franca decadência e perde cada vez mais espaço para o neotribalismo; e o racionalismo é enfraquecido pela rebelião do imaginário. A questão-chave para Maffesoli é substituir aquilo que é comumente diagnosticado como crise do contemporâneo pela percepção de que um certo paradigma ou época está em processo de encerramento.

Assim, o objetivo de Maffesoli é colocar entre parênteses a modernidade que se auto consolidou como uma marcha linear para o progresso e para a realização da perfeição por meio de uma razão iconoclasta, eliminando as impurezas e irracionalidades e todas as formas do sagrado que fazem parte disso. A saturação da modernidade significa a inversão do desencantamento, ou seja, o componente arcaico que fora combatido pelos tempos modernos retorna com força e vigor:

(...) é certo que a cultura contemporânea em seus diversos aspectos: filmes, músicas, coreografia, moda, vida cotidiana é, cada vez mais, "contaminada" por uma religiosidade ambiental na qual se misturam, sem distinção, o ocultismo, o paganismo, o neodruidismo, o xamanismo, as diversas formas de orientalismo, sem esquecer a astrologia, a bruxaria, o satanismo ou as diversas formas de New Age. $\mathrm{O}$ denominador comum desses diversos fenômenos é justamente aquele de uma abordagem existencial na qual aquilo que é primário é justamente a experiência sensível compartilhada em um quadro comunitário (MAFFESOLI, 2009, p. 176, tradução nossa).

Se cada época está marcada por um espírito do tempo, por um Zeitgeist, a nossa atmosfera e energia social não busca mais se transcender, fazer utopia: em Deus, no Estado, na Revolução. Nossa época desenvolve-se, antes, no presente, em vivências emocionais guiadas pelo ideal comunitário e pela razão sensível. A mutação é tal que a maioria das abordagens sociológicas que nos permitiam analisar as formas relacionais do social tornaram-se obsoletas. Consciente dessa mutação e diferentemente de outros intérpretes das ciências sociais obnubilados pela abordagem quantitativa ou pela postura meramente crítica, Maffesoli busca encontrar a significação dessas transformações colocando o sagrado como elemento essencial da organização social e ponto de observação privilegiado dessas mutações de fundo. 
Evidentemente, a rebelião do imaginário que caracteriza nossa contemporaneidade não significa simplesmente o retorno da religião, uma das responsáveis pela luta contra o poder da imagem, mas, antes, o retorno do poder e da efervescência do sagrado, sob formas menores. Isto é, um retorno do sagrado não tanto em suas formas institucionais e domesticadas, mas justamente naquilo que ele tem de selvagem (BASTIDE, 1975) e ambivalente (BATAILLE, 1986), visível em diferentes manifestações sociais nos quais o que está em jogo é aquilo que Otto chamou de numinosum, justamente o que provoca, ao mesmo tempo, o temor místico, a estranheza e a repulsa, bem como o sentimento de fascínio e atração irresistível por algo absolutamente outro que ultrapassa a esfera da racionalidade (OTTO, 2007).

$\mathrm{Na}$ esteira desse debate sobre a natureza paradoxal do sagrado, Maffesoli, em obras mais recentes, emprega a noção de sacral, neologismo que é utilizado para pontuar o retorno vigoroso do mistério, do desconhecido, do indivisível, ou seja, de tudo aquilo que é atrelado à esfera do sagrado e que o mito do desencantamento do mundo havia acreditado dissipar com seu rolo compressor e que doravante reencontra um vigor não necessariamente vinculado ao quadro institucional das administrações religiosas, estando, antes, no centro das próprias estruturas da socialidade contemporânea. Desse modo, o sacral é "a forma difusa de um sagrado que não se reduz à ordem do religioso, mas contamina o conjunto da sociedade” (MAFFESOLI, 2018, p. 8, tradução nossa).

Essa difusão do divino na vida cotidiana constitui, para Maffesoli, uma verdadeira infraestrutura da vida espiritual a partir da qual ocorre essa diluição da consciência individual, em sua natureza monódica, numa heterodoxia variada de identificações em funções de tribos nas quais os indivíduos pós-modernos estariam imersos. Ao partilharem um gosto esportivo, religioso, musical, político, ou mesmo as novas formas de solidariedade, sectarismos e fanatismos, todos esses pequenos grupos, que formam um mosaico complexo e heterodoxo, participam desse reencantamento. No limite, é essa nova forma de se religar ao social, por meio dessa viscosidade grupal, imagética e orgânica, que Michel Maffesoli nomeará de sacral:

Em cada um desses casos, trata-se de vibrações religiosas. Em termos mais acadêmicos denominámos: sintonia. Estar no tom? Compartilhar 
as emoções, as paixões. Todas as coisas "histéricas", naquilo que elas solicitam menos o cérebro que o ventre (usterus). E são justamente essas vibrações coletivas que, stricto sensu, colocam em relação ou, simplesmente, conectam ao outro. Sendo este relacionismo a essência mesmo do fato religioso (religare) (MAFFESOLI, 2018, p. 9, tradução nossa).

O que está em jogo nesse sacral pós-moderno, evidência do reencantamento do mundo, é o desejo de quebrar as barreiras clássicas do mundo moderno, como aquelas que separam corpo e alma, natureza e cultura, razão e imaginação, relativizando o império da verdade única e colocando em relação as verdades plurais. Tudo isso, para Maffesoli, revela a complexidade interativa do holismo pós-moderno, marcado por uma verdadeira participação mística com os outros e com a natureza, isto é, maneiras arcaicas de ser e estar no mundo nas quais "o que está em jogo é justamente aquilo que podemos chamar de mística da religação. Estar religado ao mundo e aos outros numa reversibilidade sem fim" (MAFFESOLI, 2009, p. 159, tradução nossa). Trata-se do próprio retorno do sacral que confirma a passagem de uma moral esclerosada para uma outra ética em gestação, na qual "a salvação não é mais esperada em um Paraíso distante (celestial ou terrestre), é vivida, aqui e agora, em um instante eterno. Tudo está em movimento, pontual, efêmero" (MAFFESOLI, 2009, p. 21, tradução nossa).

Fica evidente que a socialidade pós-moderna de tribos que compartilham um território, real ou simbólico, é atravessada pela intensidade própria da religiosidade. Trata-se de uma socialidade marcada por uma tecelagem social subterrânea entre indivíduos a partir de uma participação comum a um todo mais vasto do que a mera soma das partes. Nessa socialidade que se baseia na lei da contaminação, em pequenas formas de solidariedade que refletem nosso desejo irrefragável de comunicação e comunhão, a aproximação ao mistério se dá mais de maneira efusiva e orgiástica do que discursiva. Uma aproximação mediada, paradoxalmente, por meio dos novos aparatos tecnológicos, isto é, são justamente essas novas formas de tecnologias de comunicação em rede que engendram e favorecem essa ligação espiritual, ultrapassando os limites das identidades fixas. 


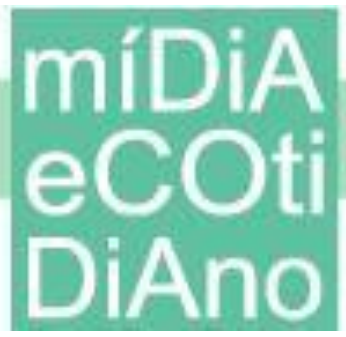

\section{A sacralidade tecnológica}

Maffesoli é preciso ao definir a pós-modernidade como a sinergia entre o arcaico e o desenvolvimento tecnológico, chamando a atenção para o fato de que estamos imersos em um mundo reencantado, sobretudo graças às novas tecnologias que potencializam esse processo paradoxal. Vivemos em um mundo devastado pelo mesmo projeto que matou Deus para substituí-lo por uma versão secular do milenarismo, e é nas ruínas desse projeto e graças ao desenvolvimento tecnológico que a potência do sagrado ressurge. Curiosamente, é em nosso tempo, aquele do desencanto com a própria ideia de desencantamento, que essas imagens que a modernidade supôs ter excluído voltam, incluindo os anjos e os demônios.

Esse reencantamento não se dá apenas pela presença das religiões nas mídias e redes digitais. Evidentemente, é fato inegável o deslocamento da religião para as redes, um deslocamento que já não espanta nem os espíritos mais conservadores. Sites institucionais, ritos online, redes sociais de fiéis, aplicativos para celulares e tabletes. Eis as inegáveis evidências de que a religião se posiciona cada vez mais intensamente no ambiente digital, provocando um tipo de experiência que vai muito além da simples disponibilização de conteúdos por novos instrumentos (AGUIAR, 2014).

No entanto, para além dessa inegável dimensão comunicativa das religiões, é necessário estar atento, como nos convida a pensar Maffesoli, às próprias especificidades da técnica digital em rede. A potência dessas redes está em seu caráter conectivo, de religação, próprio da experiência do sagrado. As redes, permitindo as diferentes representações do sagrado uma propagação fácil, favorecem uma mistura e estimulam a emergência de experiências que assumem novas e inéditas formas de sincretismos. Como nos recorda Gilbert Simondon (2014, p. 115, tradução nossa): “O uso das técnicas em rede define vias de ação e dimensões que provocam uma percepção relativizada da realidade humana e da sacralidade". As redes favorecem uma atitude de construção constante e de atualizações transitórias de representações variadas do sagrado, restituindo o encantamento ocultado pelo racionalismo moderno e pelas religiões monoteístas. A técnica é agora o vetor do reencantamento do mundo, conectando os diferentes modos de existência, humanos e não-humanos. As redes desvelam, no sentido heideggeriano, a potência do sacral. 


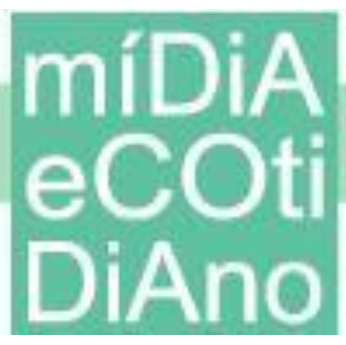

Fica claro, portanto, que mais do que a religião, o que as novas tecnologias digitais promovem é uma comunhão mística, uma religiosidade difusa e sincrética, pelo próprio caráter conectivo das novas mídias e tecnologias. Pode parecer paradoxal essa mística tecnológica, porém, como Simondon pontua, não há oposição real entre sacralidade e tecnicidade, já que a verdadeira natureza dos objetos técnicos não está somente na sua instrumentalidade. Assim, em todas as hierofanias, isto é, em todas as manifestações do sagrado, os objetos, inclusive os técnicos, desempenham um papel não negligenciável. Como assinalou Simondon, "as técnicas não são neutras em face da sacralidade: ou elas são pontos de intersecção da sacralidade, ou objetos de exclusão e rejeição" (SIMONDON, 2014, p. 88, tradução nossa.).

Conforme nos lembra Eliade, o sagrado sempre se manifesta em um objeto do mundo profano e qualquer objeto pode ser sacralizado: "Um objeto se torna sagrado na medida em que incorpora (isto é, revela) outra coisa além dele mesmo" (ELIADE, 1983, p. 25, tradução nossa.). Da sacralidade das pedras e do corpo à sacralidade digital, há sempre uma mídia do sagrado, de modo que a sacralidade é condicionada pelas materialidades. Assim, mesmo os objetos tecnológicos, a priori objetos racionais, podem ser sacralizados e gerar imaginários místicos.

Não seria diferente na época contemporânea com o advento e consolidação do digital. Desde o seu surgimento, essas novas tecnologias suscitaram toda uma mitologia particular e que se transforma em uma velocidade inédita, o que confirma o caráter não instrumental dos meios e técnicas. Se no início do fenômeno, na época do PC e das grandes interfaces informáticas, um imaginário transcendente cristalizado na imagem do ciberespaço era predominante (MUSSO, 2000; NOBLE, 1999; WERTHEIM, 2000), na atualidade, um imaginário mais imanente ganha força (AGUIAR, 2018). Representações tributárias do esquema horizontal inferido pela perspectiva reticular da comunicação e pelas estruturas rizomáticas das conexões sem fio próprias às redes e aos dispositivos móveis.

Com a difusão desses dispositivos, a internet de alta velocidade, a internet das coisas, o desaparecimento literal da máquina e um processo que faz desaparecer cada vez mais as interfaces informáticas, a concepção teórica de um mundo virtual separado do mundo real, um mundo on-line e um mundo off-line, tão comum no começo do fenômeno 


\section{míiA
eCOti
DiAno}

da internet, não se sustenta mais. Doravante, é nossa condição ontológica que muda: todo o nosso habitat está em rede, o que não é a concretização do sonho transumanista de escapar do mundo por meio do digital, mas um retorno à Terra, numa espécie de enraizamento dinâmico, como nos diz Maffesoli: "o fato de religar ('religare') todos e todas as coisas, provoca uma confiança ('religando') secreta em direção a todas as outras coisas" (MAFFESOLI, 2016, p. 43, tradução nossa).

$\mathrm{Na}$ vida cotidiana, as tecnologias não são percebidas como algo externo ao ser humano, como um simples instrumento, mas como elementos portadores de uma dignidade ontológica. Esses meios são considerados fundamentais para determinar como nós habitamos o mundo, ao lado dos elementos espirituais, naturais, etc. Para além do materialismo frenético peculiar à modernidade, que levou à devastação do mundo, Maffesoli nos convida a estar atentos ao ressurgimento do imaterial justamente a partir da técnica. Tudo está conectado pelas tecnologias e essa interconexão dá vida a elementos que forjam um novo tipo de animismo, que é o indício de uma mística mais imanente e pagã ou, em outros termos, de uma religiosidade holística. Há um retorno à origem, isto é, um desvelamento da reticularidade do mundo, próprio do contexto primitivo tal qual descrito por Simondon (2012).

Para representar esse retorno, Maffesoli emprega a imagem da espiral, imagem fértil para compreender essas novas forças de expressão do sagrado, pois, é graças às tecnologias de ponta, notadamente as digitais, que se recuperam essas dimensões que a modernidade havia acreditado ter superado, qualquer coisa que faz parte de nosso passado primitivo. Desde Mcluhan, sabemos que o meio é a mensagem (MCLUHAN, 1994). Entendido em seu sentido amplo, isto é, que a comunicação integra não apenas o significado na materialidade da troca, mas também integra o contexto, presente e passado, compreendemos de modo claro, como nos indica Maffesoli, que é o lugar que cria os laços sociais, os vínculos e a comunhão. Vivemos, portanto, em uma época de oxímoros fazendo convergir a sacralidade e a reticularidade.

Essa passagem do desencantamento ao reencantamento do mundo por meio das novas tecnologias, ou mesmo a saturação do monoteísmo em direção ao politeísmo, é uma passagem que assume diferentes cores: do espiritualismo sincrético da New Age ao tecnochamanismo contemporâneo. O que está em jogo é uma dimensão epifânica que 


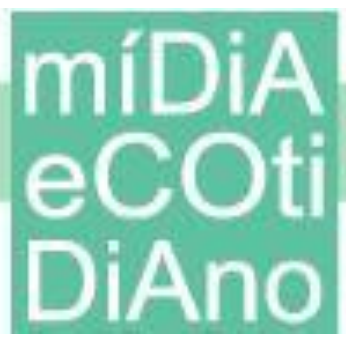

abre a experiência do sagrado ao desconhecido em uma efervescência compulsiva sincrética, muitas vezes como o resultado da sinergia entre o arcaísmo e a mística da cultura digital. Passamos de uma experiência do sagrado ligada principalmente à sua indisponibilidade, como no caso da administração religiosa monoteísta, a uma outra experiência caracterizada por sua constante disponibilidade. As experiências determinadas pelo conteúdo religioso não são mais o ponto de partida exclusivo para as práticas sociais do sagrado, mas também a técnica.

Assim, sob esta nova atmosfera trágica pós-moderna surgem não só novas formas de vivência do sagrado, mas uma outra concepção de técnica, para além do instrumentalismo trágico e mais ligada à potência do destino, sublinhando uma necessidade de radicação, de criar vínculos e raízes, colaborando na emergência dessa religiosidade ambiente, causa e efeito do sacral. Logo, a acomodação a essa época, a aprendizagem de uma nova forma de habitar uma terra devastada, exige, não uma rejeição da tecnologia, mas a busca de uma relação distinta, que, como nos alerta Heidegger (1968), deve ser baseada na serenidade.

\section{Conclusão}

O fim de um mundo não é o fim do mundo. Eis uma frase repetida exaustivamente por Michel Maffesoli ao longo de sua vasta e significativa obra com o objetivo de destacar que mesmo se o paradigma moderno esteja em processo de saturação, precisamos estar atentos a outras formas da vida social. O que Maffesoli nos sugere é que os limites perante os quais nos deparamos nesse fim de um mundo não serão o ponto no qual tudo acaba, mas o ponto a partir do qual um outro mundo passa a ser.

$\mathrm{O}$ ideal de desencantamento do mundo revelou-se enquanto mito na medida que a promessa da tecnologia, a instauração do paraíso sobre a terra pela via recta da razão, conduziu ao efeito oposto: a massificação do homem, a fuga dos deuses e a devastação da Terra. O verdadeiro oxímoro de nossos tempos é que existe um efeito inesperado da tecnologia, sobretudo as digitais em rede, que é a recuperação das dimensões esquecidas do sacral, daí a definição da pós-modernidade como a sinergia entre o arcaico e o desenvolvimento tecnológico. 
O poder do sagrado, que estava no subterrâneo da modernidade, é trazido à tona pela crise ambiental e o advento do digital, as duas grandes pressões da pósmodernidade, forjando um imaginário místico imanente marcado pelo retorno à Terra e um religare com o outro natural, societal e espiritual. Esse verdadeiro reencantamento do mundo, como destacado por Maffesoli, e que se exprime diante de nossos olhos na vida cotidiana, em todo seu aspecto bizarro, barulhento, passional e polifônico, é a prova da assertiva durkeimiana da essencial e permanente natureza religiosa do homem.

A técnica, para além do utilitarismo moderno, torna-se um lugar de irrupção do sagrado forjando uma solidariedade com o ambiente e provocando aquilo que Durkheim denominou de desejo de efervescência, reforçando a técnica como objeto de um verdadeiro culto por meio do qual acontece essa reconexão. Há algo nas novas tecnologias que é ao mesmo tempo aterrorizante (tremendum) e fascinante (fascinans), características potencializadas à medida em que ocorre a intensificação da interligação entre objetos, pessoas, natureza, enfim, do todo.

Nessa mística tecnológica pós-moderna, outras formas de associações e comportamentos parecem renascer, sendo muitas vezes acompanhados do ruído das efervescências e da dor dos partos difíceis. A perspectiva de Maffesoli forja, assim, um ângulo teórico fértil para a compressão do nosso contexto histórico, marcado pela saturação da ideia de que a civilização teria atingido, de modo linear e progressivo, sua inexorável fase secular. Os fundamentalismos e sectarismos de distintas matizes, as efervescências evangélicas, o movimento da Nova Era, o satanismo, a adoração das marcas pós-modernas, as festas rave, o neoxamanismo e o culto das celebridades estão entre as muitas evidências presentes no cotidiano que nos rememoram, finalmente, que a forma primordial do sacral é este desejo coletivo das nossas sociedades de comunhão emocional, de religação. O que há em comum em todas essas contraditórias experiências é que os novos aparatos digitais são, acima de tudo, objetos sacralizados e a própria conexão se torna uma experiência mística.

\section{Referências}

AGUIAR, C. E. S. A sacralidade digital: religiões e religiosidades na época das redes. São Paulo: FAPESP : Annablume, 2014. 
. La sacralité numérique et la mystique de la technologie. Sociétés, v. 139, n. 1, p. 97, 2018.

BASTIDE, R. Le Sacré sauvage: et autres essais. Paris: Payot, 1975.

BATAILLE, G. Théorie de la religion. Paris: Gallimard, 1986.

BONNEUIL, C.; FRESSOZ, J.-B. L'événement anthropocène: la Terre, l'histoire et nous. Paris: Éditions Points, 2016.

DURAND, G. Introduction à la mythodologie. In: La sortie du XXe siècle. Société. Paris: CNRS éd, 2010.

DURKHEIM, É. Les formes élémentaires de la vie religieuse: le système totémique en Australie. Paris: CNRS éd., 2008.

ELIADE, M. Traité d'histoire des religions. Paris: Payot, 1983.

Images et symboles: essays sur le symbolisme magico-religieux. Paris:

Gallimard, 2013.

FERRAROTTI, F. La religione dissacrante: coscienza e utopia nell'epoca della crisi. Bologna: EDB, 2013.

HEIDEGGER, M. Sérénité. In: Questions III et IV. Paris: Gallimard, 1968.

O tempo da imagem no mundo. In: Caminhos de floresta. Lisboa: Serviço de Educação e Bolsas, Fundação Calouste Gulbenkian, 2002.

A questão da técnica. Scientiæ studia, v. 5, n. 3, p. 375-398, 2007.

MAFFESOLI, M. La Violence totalitaire: essai d'anthropologie politique. Paris:

Presses universitaires de France, 1979.

Le temps des tribus: le déclin de l'individualisme dans les sociétés de masse.

Paris: La Table Ronde, 2000.

2009.

Le réenchantement du monde: une éthique pour notre temps. Paris: Perrin,

. "La question de la technique" de Martin Heidegger. Sociétés, v. 129, n. 3, p. $11,2015$.

La parole du silence. Paris: Les éditions du Cerf, 2016. 
2018.

Considérations sur le "sacral” postmoderne. Sociétés, v. 139, n. 1, p. 7-17,

MCLUHAN, M. Understanding media: the extensions of man. 1st MIT Press ed ed. Cambridge, Mass: MIT Press, 1994.

MUSSO, P. Le cyberespace, figure de l'utopie technologique réticulaire. Sociologie et sociétés, v. 32, n. 2, p. 31, 2000.

NIETZSCHE, F. Crepúsculo dos ídolos. São Paulo: Editora Companhia das Letras, 2006.

NOBLE, D. F. The religion of technology: the divinity of man and the spirit of invention. New York: Penguin Books, 1999.

OTTO, R. O sagrado: os aspectos irracionais na noção do divino e sua relação com o racional. São Leopoldo, RS: Ed. Sinodal, 2007.

SIMONDON, G. Du mode d'existence des objets techniques. Paris: Aubier, 2012.

Sur la technique (1953-1983). Paris: PUF, 2014.

VATTIMO, G. Credere di credere. Milano: Garzanti, 1998.

WEBER, M. Sociologie de la religion: économie et société. Paris: Flammarion, 2006.

WERTHEIM, M. The pearly gates of cyberspace: a history of space from Dante to the Internet. New York: W.W. Norton, 2000. 